\title{
Proposta metodológica de descrição e análise de fenômenos variáueis em textos históricos na perspectiva da Sociolinguistica Histórica
}

Methodological proposal for the description and analysis of variable phenomena in historical texts from the perspective of Historical Sociolinguistics

Paulo Ricardo Silveira Borges ${ }^{1}$ Universidade Federal de Pelotas (UFPEL)

Tatiana Keller ${ }^{2}$ Universidade Federal de Santa Maria (UFSM) DOI: https://doi.org/10.5902/2176148542608

Resumo: O objetivo deste artigo é (re)discutir, metodologicamente, uma proposta para análise de dados variáveis em textos históricos que possibilite, sob a ótica da Sociolinguística Histórica, uma reflexão mais aprofundada sobre a importância dos condicionadores sociais para o entendimento dos processos históricos de mudança linguística. Para a Sociolinguística Histórica, além da escolha dos textos, dos contextos de usos e da produção da escrita, é importante que os textos históricos analisados permitam o conhecimento das condições sociais motivadoras das mudanças. Para tanto, analisamos os resultados apresentados por Borges (2004), sobre o uso do pronome a gente, em onze peças de teatro de autores gaúchos, correspondendo a um período histórico de 100 anos. Damos atenção especial aos fatores sociais, especificados por faixa etária, sexo e classe social. Esperamos poder contribuir para os estudos no campo da Sociolinguística Histórica, em especial sobre a análise variacionista e a importância das variáveis sociais para o melhor entendimento dos processos de mudança linguística em tempo real.

Palavras-chave: Sociolinguística histórica. Metodologia de análise. Português do Brasil. Variação e mudança linguística.

1 Professor Associado na Universidade Federal de Pelotas (UFPEL). Doutor em Letras pela UFRGS-RS e Pós-Doutor em Letras pela UFRGS-RS: paulorsborges@gmail.com.

2 Pós-Doutoranda do Programa Língua e Cultura da UFBA. Professora Associada na Universidade Federal de Santa Maria (UFSM). Doutora em Letras pela PUCRS-RS: tatianakeller.ufsm@gmail.com. 


\section{Paulo Ricardo}

Silveira Borges

Tatiana Keller

Abstract: The purpose of this paper is to (re)discuss, methodologically, a proposal for the analysis of variable data in historical texts that allows, from the perspective of historical sociolinguistics, a more in-depth reflection on the importance of social conditioners for the understanding of historical processes of linguistic change. For Historical Sociolinguistics, in addition to the choice of texts, the contexts of uses and the production of writing, it is important that the historical texts analyzed enable the knowledge of the social conditions that motivate changes. To this end, we will analyze the results presented by Borges (2004), on the use of the pronoun a gente, in eleven plays by authors from Rio Grande do Sul state (gauchos), corresponding to a historical period of 100 years. We will pay special attention to social factors, specified by age group, sex and social class. We hope to be able to contribute to studies in the field of Historical Sociolinguistics, in particular on variation analysis and the importance of social variables for a better understanding of linguistic change processes in real time.

Keywords: Historical Sociolinguistics. Methodology of analysis. Brazilian Portuguese. variation and linguistic change.

Essa heterogeneidade plural e polarizada do português brasileiro, evidenciada nos estudos sincrônicos do português brasileiro contemporâneo, enraíza-se historicamente em condicionamentos de fatores da nossa sócio-história. (Rosa Virgínia Mattos e Silva). ${ }^{3}$

\section{Introdução}

A relação entre língua e sociedade vem sendo estudada pelos linguistas ao longo do tempo. A partir dos estudos de William Labov, a Sociolinguística passou a investigar, além dos casos de variação linguística (estável), em que não se verifica uma tendência de predominância de uma variante linguística sobre outra(s), também os casos de mudança em progresso (ou em curso), em que o processo de variação pode caminhar para sua resolução em favor de uma das variantes identificadas, a qual passa a generalizar-se dentro da comunidade de fala. Passou-se a utilizar nos estudos sociolinguísticos a chamada análise em tempo real para se verificar, também, se ao longo do tempo um fenômeno variável apresenta características identificadoras de mudança em progresso.

3 In: MATTOS e SILVA, Rosa Virgínia. Ensaios para uma sócio-história do português brasileiro. São Paulo: Parábola, 2004, p. 148. 
Neste trabalho, à luz dos preceitos da Sociolinguística Histórica, Proposta pretendemos analisar as condições sociais envolvidas em uma determimetodológica nada mudança linguística, ao longo de uma faixa de tempo, levando-se de descrição em conta os resultados apresentados por Borges (2004) sobre o uso do pronome a gente, em onze peças de teatro de autores gaúchos, correspondendo a um período histórico de 100 anos. Damos atenção especial aos fatores sociais, especificados por faixa etária, sexo e classe social. Para tanto, abordamos questões relacionadas à metodologia de análise de dados variáveis em Sociolinguística Histórica, à importância da escolha dos textos para o trabalho variacionista em tempo real, à análise variável dos dados obtidos nos textos e ao processo de mudança linguística em tempo real e às variáveis sociais.

O objetivo, portanto, é (re)discutir, metodologicamente, uma e análise de fenômenos variáveis em textos históricos na perspectiva da sociolinguística histórica proposta para análise de dados variáveis em textos históricos que possibilite, sob a ótica da Sociolinguística Histórica, uma reflexão mais aprofundada sobre a importância dos condicionadores sociais para o entendimento dos processos históricos de mudança linguística.

\section{Método sociolinguístico-histórico para análise de dados variáveis}

Um dos princípios fundamentais da Teoria Sociolinguística Variacionista, proposto inicialmente por Weinreich, Labov e Herzog (1968), e desenvolvido por Labov no conjunto de seus trabalhos no âmbito da sociolinguística, é o de que a sistematicidade linguística não está somente em contextos categóricos, mas também em contextos de variação. 0 estudo sociolinguístico, além de delimitar e analisar os objetos linguísticos, insere-se no estudo da realidade social, enquanto procura analisar fatores históricos, geográficos e sociais, os quais exercem influência e condicionam determinados processos ou formas de uma certa variedade dialetal.

Labov (1994) destaca que um dos objetivos principais da utilização de dados do passado nos trabalhos sociolinguísticos é justamente a possibilidade de determinarmos o que ocorreu na história de uma língua ou de uma família linguística, levando-se em conta os aspectos sociais que contribuíram para o desenvolvimento de certas mudanças. As posições de Labov aproximam a sociolinguística da linguística histórica, pelo fato de valorizarem explicações relacionadas a aspectos histórico-sociais que possibilitam o melhor conhecimento dos fenômenos sociolinguísticos no tempo real e, consequentemente, a melhor compreen- 
Paulo Ricardo

Silveira Borges

Tatiana Keller

são dos fenômenos na atualidade. A valorização do componente social associado aos processos históricos de variação e mudança linguística torna-se importante, uma vez que nem todas as mudanças têm a mesma configuração social e o mesmo tipo de propagação.

Entendendo-se que não é qualquer diferença de fala entre gerações ou entre grupos socioeconômicos que indicam mudança, pode-se supor que muitas das diferenças existentes na fala de cada grupo, ou indivíduo, são apenas variantes e nada têm a ver, em princípio, com mudança. Weinreich, Labov e Herzog (1968, p. 188), ao postularem uma teoria para a mudança linguística, enfatizam que "nem toda a variabilidade e heterogeneidade na estrutura linguística envolve mudanças, mas toda mudança envolve variabilidade e heterogeneidade". Observa-se que as mudanças em progresso estão atreladas a uma concepção variacionista da linguagem. Assim, tanto a análise de dados sociolinguísticos em 'tempo aparente' como em 'tempo real' podem indicar os caminhos e os estágios de certas mudanças e quais os fatores sociais que estão atuando para que os processos de variação e mudança ocorram.

Labov (1994, p. 44) apresenta duas modalidades de estudo dos fenômenos envolvendo mudança linguística: o estudo de painel ( $p a-$ nel study), que consiste no recontato dos mesmos informantes tempos depois; e o estudo de tendências (trend study), que consiste em constituir uma segunda e nova amostra representativa. Através do princípio da uniformidade (uniformitarian principle), proposto por Labov (1972, p. $275)^{4}$, pode-se identificar o quanto do passado ainda continua entre nós, levando-se em conta a observação do desenvolvimento de determinado fenômeno linguístico no presente, para que se possa deduzir um processo que ocorreu no passado.

O pressuposto associado à noção de mudança em progresso leva em conta o fato de que, se o uso de uma variante inovadora for mais frequente entre os jovens, decrescendo em relação à idade de outros informantes, tem-se uma situação clássica de mudança em progresso. Entretanto, Labov (1994, p. 56) valoriza o que denominou de "análise multivariável de dados contínuos", ao acreditar que uma mudança linguística geralmente é resultado de muitos fatores que atuam simultaneamente. E acrescenta:

4 "Uniformitarian Principle: the forces that operate to produce linguistic change today, are of the same kind and order of magnitude as those which operated five or ten thousand years ago" (LABOV, 1972: 275). 
Em geral, nenhuma amostra pode representar em proporções iguais todos os fatores que influenciam sobre a variável dependente. Como resultado, a particular distribuição em tempo aparente pode realmente refletir a distribuição de outras variáveis na população (LABOV, 1994, p. 56).

Deve-se ressaltar que, mesmo que a distribuição por níveis etários seja um importante método para a verificação de uma determinada mudança linguística, não representa uma mudança na comunidade como um todo, mas sim um padrão característico da estratificação por idade que está representado em todas as gerações (cf. LABOV, 1994, p. 73). É o que se verifica, por exemplo, no caso do uso da forma inovadora a gente, como já foi demonstrado em trabalhos anteriores, sejam com dados de fala culta (LOPES, 1993; MONTEIRO, 1994; ZILLES, 2002), como de fala popular (OMENA,1986/1996 e BORGES, 2004), ao evidenciarem que a variante inovadora a gente foi mais frequente entre os jovens, o que indica uma clara situação de mudança em progresso. O estudo transversal, amparado na análise da mudança em 'tempo aparente', mostra-se relevante para a identificação de uma mudança em progresso, em função da distribuição das variáveis por nível de idade.

Os trabalhos variacionistas em Sociolinguística Histórica, no nosso entender, devem possibilitar uma análise que permita o diálogo entre o passado e o presente, estabelecendo-se mecanismos que indiquem como ocorreu certa mudança motivada pelo uso variável de determinado aspecto linguístico pelos indivíduos no decorrer do tempo. Para tanto, acreditamos que uma das possibilidades para a verificação de processos de variação e mudança é a utilização de textos literários, de diferentes períodos históricos, textos esses típicos da cultura e da linguagem de uma determinada comunidade em um período histórico específico. Nesse aspecto, Conde-Silvestre (2007, p. 45) destaca que:

\footnotetext{
Sin duda, los textos más útilis para el investigador son aquellos que transladan al medio escrito intercambios comunicativos que han ocurrido o podrían haber ocurridos en el medio oral pues, en principio, este tipo de textos debería manifestar un grado mayor de variación y, por otro lado, facilitar la correlación de las variables linguísticas con las circunstancias personales de sus emisores y receptores (CONDE- SILVESTRE, 2007, p. 45).
}

Proposta metodológica de descrição e análise de fenômenos variáveis em textos históricos na perspectiva da sociolinguística histórica 
Paulo Ricardo

Silveira Borges

Tatiana Keller

\subsection{Sociolinguística Histórica}

Nevalainen e Raumolin-Brunberg (2012) mencionam que o termo Sociolinguística Histórica surgiu nos últimos trinta anos e que uma das primeiras pesquisadoras a fazer referência a ele foi Romaine (1982), cujo estudo procurou avaliar de que forma o modelo quantitativo da sociolinguística variacionista poderia ser aplicado a dados históricos. Os autores comentam ainda que, nos anos 80, a variação dos tipos de gêneros textuais tornou-se um dos temas mais pesquisados em sociolinguística histórica; nos anos 90, conforme os autores, a atenção voltou-se para o estudo da variação histórica regional e demográfica, especialmente, por causa do uso de documentos pessoais, como cartas e diários; já, nos anos 2000, muitas linhas de pesquisa se consolidaram nessa área: análises qualitativas e quantitativas sobre várias línguas, estudos sobre redes sociais e mudança de código, investigação de fenômenos sociopragmáticos e interacionais ${ }^{5}$.

Romaine (1982) comenta que o objetivo da Sociolinguística Histórica é fornecer um modo de dar conta de formas e de usos nos quais a variação pode se manifestar ao longo do tempo. De forma semelhante, Marquilhas (2015, p. 214) alude que o objetivo da Sociolinguística Histórica é estabelecer uma possível correlação entre dados linguísticos do passado e a realidade social do mesmo período. Nesse sentido, Hernandez-Campoy e Conde-Silvestre (2012, p.1) definem a Sociolinguística Histórica como a reconstrução da história de uma dada língua em seu contexto sociocultural. Os autores mencionam ainda que um dos feitos mais relevantes dessa disciplina é a possibilidade de diálogo na pesquisa linguística entre o passado e o presente. Desse modo, a Sociolinguística Histórica permite a superação da dicotomia entre sincronia e diacronia ${ }^{6}$.

Labov (1994) aponta como ponto forte da linguística histórica sua capacidade de acompanhar mudanças linguísticas ao longo do tempo, mas também menciona que seu ponto fraco é o fato de que a documentação de que se dispõe para análise sobreviveu por acaso e pode ser incompleta e defeituosa. Mattos e Silva (2006 [1991]) já fazia referência a essa dificuldade dizendo que, ao lidar com dados de sincronias passadas, o pesquisador fica limitado apenas aos documentos escritos que resistiram ao tempo e a acidentes históricos, uma vez que não é mais

5 Russi (2016, p. 1-3) apresenta um levantamento das obras produzidas no âmbito da Sociolinguística Histórica nos últimos 30 anos. Além disso, a autora menciona também o lançamento, em 2015, do periódico Journal of Historical Sociolinguistics pela De Gruyter (https://www.degruyter.com/view/j/jhsl?lang=en). 6 A esse respeito, indicamos a leitura de Aitchison (2012). 
possível contar com a ajuda de falantes nativos daquela variedade. Labov (1994) comenta ainda que o pesquisador, nessa perspectiva, tem de enfrentar a tarefa de explicar as diferenças entre o passado e o presente; contudo, saber em que medida o passado é diferente do presente é algo difícil de precisar (Historical Paradox).

Entendemos ser possível desenvolver uma metodologia de análise que contemple a possibilidade de examinar fatores sociais condicionantes dos processos variáveis em um determinado momento do passado. Ao correlacionarmos os fatos do passado com o presente, podemos obter explicações sobre quais fatores linguísticos e sociais ocorreram no passado e se esses fatores continuam, em maior ou menor escala, a ocorrer no presente.

Buscamos, no presente texto, mostrar como é pertinente uma seleção criteriosa de textos literários, representativos de um determinado gênero, para a análise na perspectiva da Sociolinguística Histórica, principalmente no que diz respeito à quantificação e à análise de dados sociolinguísticos. Acreditamos que alguns textos são mais propícios para a identificação e o reconhecimento dos aspectos linguísticos variáveis correlacionados com os componentes sociais, uma vez que certas marcas sociais e estilísticas podem ser reveladoras de atributos sociais como sexo, faixa etária, classe social, escolaridade, entre outras. Nesse particular, Marcotulio et al. (2018, p. 14-15), ao citarem os princípios da Sociolinguística Histórica para o estudo das fontes documentais históricas, enfatizam a importância de "compreender e explicar os processos de mudança concretos do português a partir da correlação entre os fatores linguísticos e sociais".

\section{A importância da escolha dos textos para os estudos em Sociolinguística Histórica}

Embora Labov (1972, p. 98) mencione que o linguista que lida com dados históricos faz o melhor uso de um dado ruim (bad data problem), Romaine (1982, p. 122) argumenta que um dado histórico só pode ser considerado ruim quando comparado a um dado de fala real; a autora diz ainda que documentos históricos escritos deveriam ser considerados válidos por si só.

Ayres-Bennet (2018, p. 257) tece alguns comentários sobre os desafios encontrados pelo pesquisador em Sociolinguística Histórica para a obtenção de dados. A autora remete ao fato de que os dados disponíveis são menos numerosos se comparados aos dados de língua falada;
Proposta metodológica de descrição e análise de fenômenos variáveis em textos históricos na perspectiva da sociolinguística histórica 
Paulo Ricardo

Silveira Borges

Tatiana Keller

se recuamos no tempo, textos escritos por mulheres e por pessoas de níveis sociais mais baixos são mais escassos. Além disso, a pesquisadora salienta que frequentemente temos menos informações sobre os informantes, o que pode dificultar a construção de seu perfil social em termos de idade, gênero, ocupação, educação, status socioeconômico etc. Por fim, Ayres-Bennet (2018) fala sobre a necessidade de se levar em conta, na análise histórica, o papel exercido pela norma padrão sobre a escrita e também a questão da autoria (diferenças entre autor material e autor intelectual, por exemplo).

Os dados sociolinguísticos extraídos de texto históricos, que buscam descrever contextos de fala, devem representar o mais fidedignamente possível os aspectos sociais relacionados à determinada comunidade de fala, como também as características idiossincráticas próprias aos indivíduos que pertencem a essa comunidade. Ernst (1980, p. 3, apud AYRES-BENNET, 2018, p. 258) lista como fontes possíveis de apresentar características da língua falada do passado os seguintes tipos de material: 1) transcrições históricas de fala autêntica; 2) modelos de diálogos em textos didáticos; 3 ) discurso direto em textos ficcionais do gênero teatral e de outros gêneros, tal como o narrativo; 4) textos metalinguísticos, como as gramáticas, por exemplo; 5) dados comparativos de língua falada em diversos períodos. Para este trabalho, foram selecionados diálogos extraídos de onze peças teatrais de autores gaúchos, abrangendo um período de 100 anos (de 1890 a 1990).

Para a Sociolinguística Histórica, é importante que os textos selecionados para análise possam apresentar tanto as variações sociais como as variações estilísticas, pois ambas desempenham papéis fundamentais nos processos de variação e mudança ao caracterizarem os distintos subgrupos pertencentes a uma sociedade heterogênea, possibilitando que se possa adequar os indivíduos nos diferentes contextos imediatos de usos (cf. LABOV, 1972, p. 271).

Schneider (2002, p. 71), nesse aspecto, destaca que os textos históricos utilizados para análises sociolinguísticas devem fornecer uma quantidade considerável de variantes individuais que permitem análises quantitativas correlacionadas a diferentes aspectos sociais. Os textos nos quais os escritores trazem as falas mais autênticas dos indivíduos de uma comunidade, caracterizando traços sócio-históricos típicos de determinada época, são os mais indicados para as análises sociolinguísticas que busquem a correlação entre o comportamento linguístico de uma comu- 
nidade ou indivíduos com os aspectos sociais característicos e marcantes da sua realidade social. Schneider (2002, p. 73) ressalta, ainda, que é comum que os escritores citem "exemplos de frases típicas de outros que ele considera características do seu discurso e que ouviu várias vezes". Poderíamos dizer que os textos que apresentam frases socialmente contextualizadas e indicativas de situações reais de usos da língua por determinada comunidade de fala, em um período histórico específico, são valiosos repositórios de manifestações sociolinguísticas históricas reveladoras das relações entre língua e sociedade.

Conforme Romaine (1982), é possível reconstruir determinadas variáveis sociais a partir do estudo dos estilos e registros encontrados em textos históricos e que denunciam contextos de fala associados a características sociais de grupos e/ou indivíduos de uma comunidade de fala. Para tanto, a compreensão dos fatores sociais que determinam as condições variáveis de uma língua, em qualquer período, torna-se importante para a verificação das correlações entre língua e sociedade e para a identificação das forças sociais que impulsionam as mudanças.

Ao falar sobre a utilização de textos escritos para a identificação de fenômenos variáveis em trabalhos de Sociolinguística Histórica, Romaine (1982, p. 121) destaca algumas dificuldades envolvidas na reconstrução de contextos de registro histórico. Nesse aspecto, cabe frisar que não é sempre que os componentes histórico-sociais trazem indicativos extralinguísticos relevantes que possam contribuir para as análises sociolinguísticas. Por isso, Romaine (1982, p. 122) enfatiza a importância do uso de textos de épocas passadas, uma vez que, conforme a autora, “os dados históricos podem ser válidos por direito próprio (como podem outros casos da linguagem escrita), independentemente da extensão em que eles refletem ou são removidos das produções de falantes nativos".

Maia (2012, p. 538) entende que determinados requisitos como autenticidade, confiabilidade e diversidade de tipologia de textos são necessários às fontes escritas históricas para uma pesquisa de caráter diacrônico. A autora ressalta que os corpora textuais devem "reflectir fielmente as características linguísticas dos manuscritos, uma vez que nelas se reflectem as marcas da variação da língua da época". Sendo assim, é importante uma escolha criteriosa por parte do pesquisador sobre o tipo de texto a ser utilizado como corpus para a análise em Sociolinguística Histórica.
Proposta metodológica de descrição e análise de fenômenos variáveis em textos históricos na perspectiva da sociolinguística histórica 
Reconstruir e entender a história social do passado, a partir dos componentes sociais presentes nos diálogos encontrados em textos de teatro, por exemplo, de diferentes períodos históricos, pode ser uma estratégia interessante para a verificação dos comportamentos sociais motivadores de determinadas variações e mudanças, como rastros indicativos do comportamento sócio-histórico e linguístico de uma comunidade. No nosso entender, não se trata de não ter controle dos dados

Paulo Ricardo Silveira Borges

Tatiana Keller ou da utilização de dados "ruins" ou fragmentados [cf. Labov, 1972, p. 100], mas perceber que a análise com base na Sociolinguística Histórica pode revelar contextos sociais próprios e indicadores de relações entre língua e sociedade, representadas e estratificadas por classe social, faixa etária, sexo, escolaridade. Por outro lado, sabemos também, como destacou Medina Morales (2005), que fatores sociais como sexo, idade, classe social e escolaridade, comumente levados em consideração em análises sincrônicas atuais, precisam ser relativizados no âmbito da Sociolinguística Histórica, justamente em função da escassez de textos onde se possa controlar essas variáveis e estabelecer determinados critérios que identifiquem o que a autora chama de redes sociais.

Rosa (2015), por sua vez, ao referir-se aos procedimentos de análise em Sociolinguística Histórica, acredita ser possível seguir as mesmas etapas utilizadas em trabalhos de sociolinguística variacionista, atentando-se para os seguintes procedimentos:

\footnotetext{
a) delimitação da variável dependente; b) descrição das variáveis independentes linguísticas e/ou extralinguísticas (que poderiam, por hipótese, estar influenciando a variável dependente); c) coleta de dados; d) transcrição e codificação dos dados coletados; e) quantificação dos dados por meio de um programa de regra variável (ROSA, 2015, p. 9).
}

É possível, portanto, a utilização das mesmas ferramentas tanto para a análise sincrônica como para a diacrônica, embora saibamos que a quantidade de dados utilizados nos trabalhos diacrônicos geralmente são menores. Para que esses procedimentos sejam contemplados na perspectiva de uma análise diacrônica, é fundamental ainda que o pesquisador em Sociolinguística Histórica leve em conta, ainda, outros procedimentos quanto à constituição do corpus para a análise, uma vez que a escolha dos textos deverá respeitar determinados parâmetros que 
são fundamentais para uma análise de dados que seja criteriosa e devidamente amparada na metodologia variacionista sociolinguística. Para tanto, Montgomery (2007, p. 121-124) traz algumas sugestões que devem merecer atenção especial no que se refere às investigações em Sociolinguística Histórica, como a importância da escolha do tipo de texto, o período histórico do texto, as informações histórico-sociais contidas no texto, a região de origem do texto e do autor e os padrões sociais de língua utilizados no texto. Todos esses dados são relevantes para a constituição da amostra a ser trabalhada.

Ao trazermos as variáveis sociais para uma perspectiva de análise sócio-histórica, buscamos vislumbrar situações de fala descritas em textos de teatro, escritos por autores gaúchos, com personagens estratificados por classe social em diferentes épocas. Como afirma Lucchesi (2017, p. 378), “análises de mudanças em tempo real são factíveis, sobretudo a partir do século XIX, em face da ampla gama de materiais disponíveis na documentação escrita supérstite, tais como: jornais, peças de teatro, cartas pessoais etc." Tais documentos constituem-se como importantes fontes para os estudos das mudanças em tempo real, pois possibilitam o estudo da linguagem não apenas de uma determinada classe dominante, mas também de classes sociais inferiores, representativas de linguagens mais populares de uma determinada comunidade de fala.

\section{Uma proposta metodológica de análise variacionista na perspectiva da Sociolinguística Histórica}

Os registros encontrados em textos antigos são repositórios de situações indicativas de variações linguísticas, especialmente se os textos refletirem usos cotidianos de representações de fala de uma comunidade. Romaine (1982) destaca determinados "padrões" existentes nas escolhas feitas tanto por falantes como por escritores. Esses "padrões" são influenciados por fatores e condições sociais próprios aos contextos de comunicação, seja na fala como na escrita. Nesse sentido, também os dados obtidos de textos, próprios à língua escrita, podem ser submetidos à metodologia de análise variacionista, levando-se em conta tanto os fatores linguísticos como os fatores extralinguísticos. Preti (1974), ao referir-se à importância da linguagem dos personagens em obras literárias, tais como os exemplos expressivos encontrados em peças de teatro, destaca que:
Proposta metodológica de descrição e análise de fenômenos variáveis em textos históricos na perspectiva da sociolinguística histórica 
Em todas as épocas, muitos literatos aproveitaram em suas obras a fala contemporânea, e se não o fizeram no plano narrativo, onde a identificação entre a linguagem do escritor e o narrador é mais imediata, pelo menos o tentaram nas falas de suas personagens, criando um diálogo mais próximo da realidade falada (PRETI, 1974, p. 42).

Paulo Ricardo Silveira Borges

Tatiana Keller

Nesse aspecto, Silva Neto (1960) já referira a importância da análise linguística na perspectiva sócio-histórica, ao destacar que os fatos do passado contribuem para a reconstrução da história social do português, haja vista que a língua é um instrumento social que caminha junto com a história social. A proposta de análise apresentada para este trabalho, com base na Sociolinguística Histórica, parte de um corpus organizado por Borges (2004), composto por onze peças de teatro de autores gaúchos, abrangendo um período de cem anos, que se estende de 1896 até 1995, com intervalos de dez anos entre uma obra e outra. Os textos selecionados indicam os cotidianos linguísticos de grupos sociais e indivíduos que utilizam variedades urbanas, haja vista que são textos de peças de teatro em que estão representadas as falas de pessoas de diferentes estratos sociais em situações tidas como "reais" de usos em sociedade.

Oliveira (2005), ao avaliar a representatividade do trabalho com textos históricos escritos como fontes sócio-histórica variacionistas, destaca que somente sejam utilizados para os trabalhos os dados que reflitam comportamentos reais próprios à língua falada. Diz o autor:

Minha proposta é a de que só sejam utilizados como evidência de processos de variação/mudança aqueles dados que A - se mostrarem quantitativamente significativos, e B- decorrerem de uma teoria linguística (da língua falada) que tenha alcançado um nível explicativo (e não apenas os níveis observacional e descritivo) (OLIVEIRA, 2005, p. 173).

Como as peças de teatro foram escritas para serem dialogadas, supostamente mais próximos da fala efetivamente produzida ou, pelo menos, distintas de outros gêneros como o narrativo, espera-se que representem um importante corpus para os estudos sociolinguísticos, uma vez que os diálogos tendem a recriar, em maior ou menor grau, a lingua- 
gem cotidiana das pessoas. As peças de teatro expressam manifestações linguísticas urbanas utilizadas por personagens moradores de cidades do Rio Grande do Sul e fazem parte de um banco de textos de teatro de autores gaúchos, que hoje compõem acervo pertencente ao Grupo de Pesquisa "Memória Linguística e Social do RS: Estudos Diacrônicos"7. No Quadro 1 , descrevemos o corpus sob análise, em que constam o nome da obra, o autor e o ano. As referências bibliográficas detalhadas das obras de teatro constam em item disposto após as "Referências" deste trabalho.

\section{Quadro 1 - Obras e períodos das peças de teatro utilizadas}

\begin{tabular}{|l|c|}
\hline \multicolumn{1}{|c|}{ Obra / autor / ano } & Período \\
\hline 1 - A Viúva Pitorra (Simões Lopes Neto) - 1896 & 1890 \\
\hline 2 - A ciumenta velha (Joaquim Alves Torres) - 1905 & 1900 \\
\hline 3 - Nossa terra (Abadie Faria-Rosa) - 1917 & 1910 \\
\hline 4 - Adão, Eva e outros membros da família (Álvaro Moreira) - 1927 & 1920 \\
\hline 5 - Iaiá Boneca (Ernani Fornari) - 1938 & 1930 \\
\hline $\begin{array}{l}\text { 6 - Seis anos de rádio: história anedótica de Pery \& Estellita (Pery Borges) - } \\
\text { 1942 }\end{array}$ & 1940 \\
\hline 7 - Quando elas querem (Paulo Hecker Filho) - 1958 & 1950 \\
\hline 8 - A ponte (Valdir Ruzicki) - 1962 & 1960 \\
\hline 9 - Pode ser que seja só o leiteiro lá fora (Caio Fernando Abreu) - 1974 & 1970 \\
\hline $\begin{array}{l}\text { 10 - Bye, bye sweet home! A barra do tribunal, Casinha pequenina, Tudo no } \\
\text { divã (Ivo Bender) - 1983 }\end{array}$ & 1980 \\
\hline 11 - A coisa certa (Júlio Conte) - 1995 & 1990 \\
\hline
\end{tabular}

FONTE: Borges (2004)

\section{0 fenômeno linguístico analisado e as variáveis sociais utilizadas}

Esta proposta de análise trata do processo de variação entre as formas pronominais nós vs. a gente, dando-se ênfase para as ocorrências da forma inovadora a gente, característica da língua portuguesa brasileira, e que mereceu relevantes estudos por parte de diferentes autores, tanto em trabalhos na perspectiva de tempo real como de tempo aparente: Lopes (1999), Borges (2004), Omena (1986, 1996), Borba (1993), Zilles (2002, 2007), Seara (2000), Menon (1996), Mambrini (2004).

7 O Grupo de Pesquisa "Memória linguística e social do RS: estudos diacrônicos" foi criado em 2019 e é composto por fontes documentais do Rio Grande do Sul dos séculos XVIII, XIX e XX. Compõem o Grupo de Pesquisa, pesquisadores das seguintes universidades gaúchas: UFRGS, UFPEL, UFSM, FURG e UNIPAMPA.
Proposta metodológica de descrição e análise de fenômenos variáveis em textos históricos na perspectiva da sociolinguística histórica 
Lopes (1999) demonstra que os primeiros indícios da substituição de nós por a gente deu-se no século XVI, fortalecendo-se no século XIX. A partir da segunda metade do século XX, conforme Borges (2004), há um avanço considerável no uso da forma a gente, em variação com a forma nós, propagando-se o uso do novo pronome na linguagem dos brasileiros independentemente do estrato social. Nesse aspecto, Borges (2004) destaca que:

Paulo Ricardo

Silveira Borges

Tatiana Keller

64
Tudo indica que o processo de cristalização da forma pronominal a gente teve início no século XIX, a partir da especialização de seu uso que, de certa forma, ainda estava atrelado à referência genérica (BORGES, 2004, p. 31).

A seleção dos dados para esta análise privilegiou os casos de $a$ gente vs. nós expressos apenas na função sintática de sujeito. Foram computados um total de 246 casos, distribuídos da seguinte forma: 122 casos de a gente (49,6\%) e 124 casos de nós ( 50,4\%).

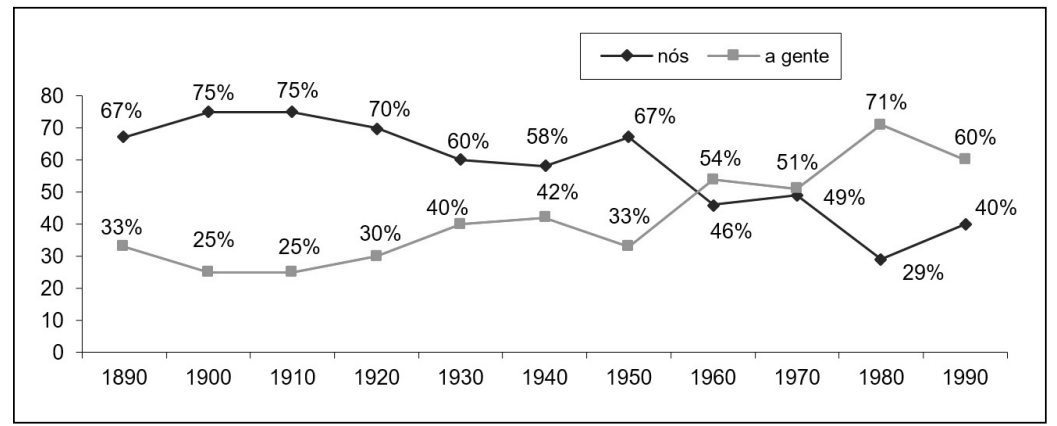

Gráfico 1: Percentuais de a gente e nós nas onze peças de teatro analisadas.

FONTE: Borges (2004, p. 55).

O Gráfico 1 demonstra que a partir da década de 1960 houve um acréscimo considerável nos percentuais de uso de a gente, superiores a $50 \%$, indicando uma mudança em curso, como destacou Borges (2004):

A partir da década de 1960 a curva ascendente fica mais pronunciada, deixando clara a competição entre as formas nós vs. a gente, como também a aceleração do processo que, dadas as proporções, a direção e as evidências já registradas na literatura, se configura como mudança em curso. Da década de 1960 em 
diante, a forma a gente expressa tem sempre percentual superior a 50\%, bem acima dos percentuais das décadas anteriores, superando também a forma nós (BORGES, 2004, p. 55).

É fundamental caracterizar a relevância dos fatores sociais para os trabalhos com textos históricos. Para tanto, trazemos aqui uma análise que leva em conta preceitos variacionistas, próprios à Sociolinguística Histórica, com o objetivo de tentar explicar, a partir dos dados do passado, determinados aspectos sociolinguísticos encontrados no presente. Nesse aspecto, Lopes et al. (2010, p. 241), ao falarem sobre a importância do papel sociocultural na escolha dos corpora históricos, destacam que "devemos ter o cuidado necessário para não tratar o indivíduo desconectado do todo". São três as variáveis sociais utilizadas como extralinguísticas: faixa etária, sexo e classe social.

A hipótese geral associada à variável faixa etária é de que os falantes mais velhos utilizam mais as formas conservadoras, enquanto que os mais jovens preferem as formas inovadoras. $\mathrm{Na}$ análise do processo de variação e mudança envolvendo a forma a gente, a variável faixa etária torna-se importante para que se possa verificar o(s) estágio(s) de uma mudança em progresso. Como as mudanças linguísticas se movem através do tempo, os efeitos podem ser detectados pelas mudanças históricas em tempo real. Eckert (2007, p. 151), nesse aspecto, destaca que "a estratificação etária das variáveis linguísticas pode refletir a mudança na fala da comunidade, pois ela se move através do tempo". A faixa etária faz parte de um conjunto de fatores 'multivariável' socialmente, não podendo ser estudada separadamente, e sim como uma variável que reflita determinadas práticas, significados e experiências associadas a estágios de vida. A inter-relação da variável faixa etária com as variáveis sociais sexo e classe social, pode trazer resultados significativos que reflitam mais claramente as relações entre língua e sociedade.

Quanto à variável sexo, Labov (2001, p. 319) ressalta que a comparação entre os padrões de classe social de homens e mulheres tem ajudado no entendimento do papel do sexo nas mudanças linguísticas. Eckert (1997, p. 215) também salienta que as categorias sociais podem ser mais salientes para os membros de um sexo do que para o outro, identificando essa categoria como relevante para os estudos variacionistas. Como sabemos, as variáveis sociais faixa etária, sexo e classe social, como categorias sociais identitárias, estão em constante dinamismo e, em muitos casos, sendo inter-relacionadas e multivariáveis.
Proposta metodológica de descrição e análise de fenômenos variáveis em textos históricos na perspectiva da sociolinguística histórica 
Paulo Ricardo

Silveira Borges

Tatiana Keller

Cabe destacar que também os processos de mudança linguística envolvem variação social, uma vez que, no curso de uma mudança, alguns membros da comunidade de fala estarão usando a forma nova e outros utilizando a forma velha. Um dos fatores presentes na constituição da variável classe social é a escolaridade que, juntamente com outras dimensões sociais como renda, profissão e local de moradia, contribuem para as condições sociais de produção da linguagem, em um dado momento histórico, de um espaço e de um contexto discursivo.

Para Amaral (2003), a variável classe social pode ser estruturada levando-se em conta três dimensões: econômica, profissional e educacional:

Em uma comunidade de fala há classes com interesses sociais e econômicos e com manifestações culturais e linguísticas diferentes. Provavelmente, então, essas classes têm uma visão da realidade e do modo de resolver seus problemas igualmente diferente (AMARAL, 2003, p. 194).

Ao tratar da variável classe social, Guy (1987, p. 37) salienta que “as divisões de classe estão essencialmente baseadas no status e poder na sociedade". Dentro dessa perspectiva, propõe a divisão da sociedade em várias classes conforme renda, bens, local de moradia, ocupação e escolaridade. $O$ autor entende, também, que os processos de mudança linguística envolvem variação social, devido às múltiplas relações que os grupos e os indivíduos desempenham em uma comunidade. Nesse aspecto, Labov (1972, p. 249) já evidenciara a relação entre status social com as variáveis linguísticas, ao apresentar as noções de prestígio aberto e de prestígio encoberto. 0 "prestígio aberto" expresso de maneira geral, de forma pública e correspondendo à boa reputação de que gozam algumas variedades de fala; o "prestígio encoberto", em oposição, atrelado à valorização inconsciente de formas linguísticas (não necessariamente da língua padrão). A variação linguística, nessa perspectiva, estaria atrelada a aspectos relacionados com as próprias diferenças sociais e culturais, intrínsecas à hierarquia das diferentes sociedades.

Para este trabalho, aspectos como renda, ocupação profissional, escolaridade e local de moradia foram controlados, levando-se em conta a descrição dos personagens, para caracterizar a variável classe social referente aos diferentes personagens pertencentes às peças de teatro utilizadas, distribuídos em três classes: classe baixa; classe média; classe alta. 


\section{A progressão da mudança em tempo real e as variáveis sociais}

Borges (2004) utilizou, para a análise estatística dos dados variáveis apresentados aqui, o programa Varbwin: Varbrul através do windows. Os resultados para as variáveis sociais faixa etária, sexo e classe social indicam que: (1) os personagens da faixa etária intermediária (de 26-49 anos) foram os que mais utilizaram a gente, com percentual de $53 \% \mathrm{e}$ peso relativo de 0,$54 ;(2)$ a forma inovadora a gente foi favorecida pelas personagens femininas, tanto em percentual (56\%) como em peso relativo $(0,56) ;(3)$ o uso de a gente foi favorecido pelos personagens da classe baixa, com percentual de $54 \%$ e peso relativo de 0,56 .

Com relação à faixa etária, o Gráfico 2 revela que os personagens com menos de 50 anos mostraram-se mais favoráveis ao uso da forma inovadora a gente, indicando um processo de mudança em curso impulsionado pelos jovens, caracterizando-se como uma mudança geracional, como identificara Labov (1994, p. 84).

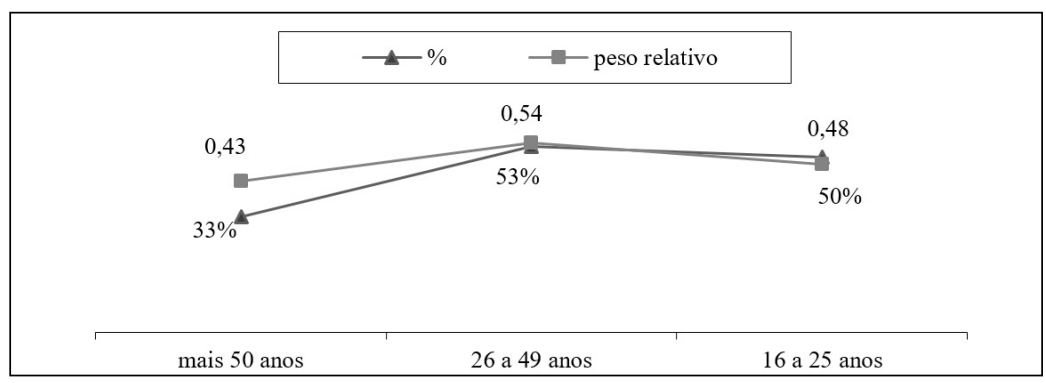

Gráfico 2: Percentuais e pesos relativos para o uso de a gente por faixa etária para as onze peças de teatro analisadas.

FONTE: adaptado de Borges (2004, p. 54)

Os resultados para a variável sexo nas peças de teatro, conforme o Gráfico 3, refletem o que também foi encontrado no trabalho de Zilles (2007), em tempo real, com dados do Varsul sobre o uso de a gente em Porto Alegre, Rio Grande do Sul, com as mulheres superando os homens tanto em percentuais como em pesos relativos: mulheres $(69 \% / 0,53)$, homens $(59 \% / 0,43)$. Para as peças de teatro, verificou-se que a mudança em progresso foi implementada pelas mulheres, haja vista que os resultados para o uso de a gente, tanto em percentual (56\%) como em peso relativo $(0,56)$, superaram os dos homens.
Proposta

metodológica

de descrição

e análise de

fenômenos

variáveis

em textos

históricos na

perspectiva da

sociolinguística

histórica

67 


\section{Paulo Ricardo}

Silveira Borges

Tatiana Keller

68

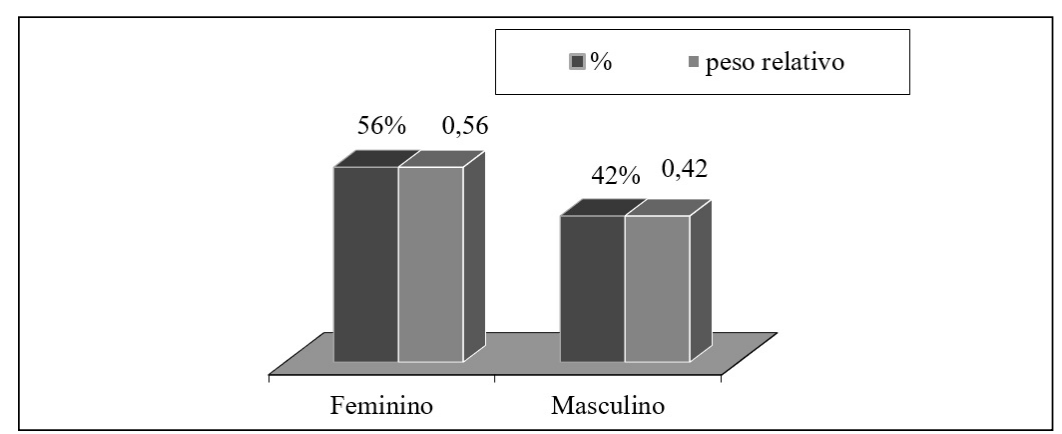

Gráfico 3: Percentuais e pesos relativos para o uso de a gente por sexo para as onze peças de teatro analisadas.

FONTE: adaptado de Borges (2004, p. 54).

Quanto à variável classe social, verifica-se, conforme o Gráfico 4, que o processo de mudança em progresso nos textos de teatro ocorreu 'de baixo para cima', haja vista que a classe baixa favoreceu o uso de a gente. A variável classe social sinaliza que a forma inovadora a gente foi utilizada pelas camadas menos privilegiadas, a partir de uma correlação direta entre status social mais baixo e maior incidência de formas não-padrão, uma vez que os percentuais de $54 \%$ para a classe social baixa e de $51 \%$ para a classe média estão bem acima do percentual de $33 \%$ da classe alta.

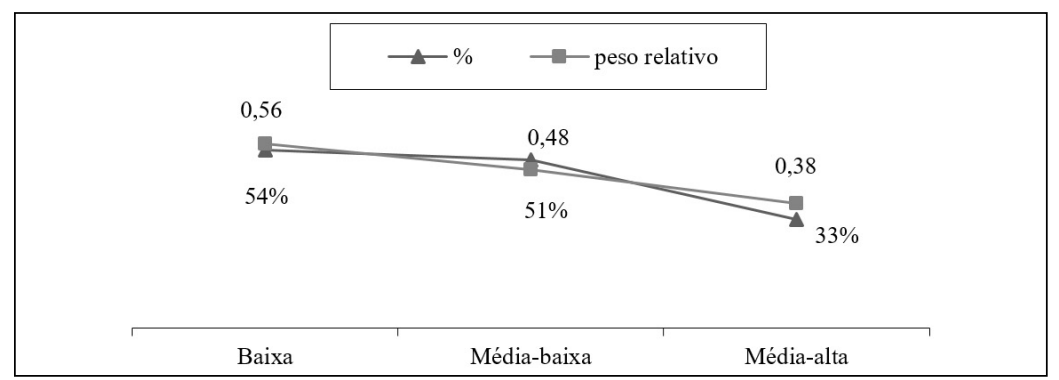

Gráfico 4: Percentuais e pesos relativos para o uso de a gente por classe social para as onze peças de teatro analisadas.

FONTE: adaptado de Borges (2004, p. 54)

O uso de a gente nas peças de teatro é favorecido, portanto, pelos personagens da faixa etária jovens (abaixo de 50 anos), personagens femininas, e personagens pertencentes à classe social baixa. Os resultados da

8 Conforme especificações para as mudanças linguísticas propostas por Labov (1994, p. 78): change from above e change from below. 
análise social das peças de teatro de autores gaúchos (1896 - 1995) sugere que o processo intensificou-se a partir da década de 1960, motivado talvez por significativas transformações sociais ocorridas em nosso país, estando estratificado pelas diferentes camadas sociais da comunidade gaúcha.

A partir dos resultados apresentados, entendemos que algumas considerações devam ser formuladas para que se possa aprimorar os pressupostos metodológicos para as análises variacionistas, na perspectiva da sociolinguística histórica, com o objetivo de melhor atender às considerações propostas pelos autores referidos no decorrer deste texto e aprimorar ainda mais a escolha dos corpora, a quantidade dos dados, as análises e os resultados estatísticos. Para tanto, considerando-se a amostra referente às peças de teatro aqui utilizadas e a metodologia de análise, propomos um aprimoramento quanto aos procedimentos de análise sociolinguística histórica que leve em conta: (1) a inclusão, caso seja possível, de outra(s) peça(s) de teatro escrita(s) por autor(es) gaúcho(s) do período histórico do final do século XIX, para que se possa cotejar os resultados com os encontrados na peça “A Viúva Pitorra", de João Simões Lopes Neto; (2) o acréscimo de duas novas peças de teatro de autores gaúchos, representando dois novos períodos históricos mais recentes: uma da década de 2000 e outra da década de 2010, para que a análise em tempo real passe de 100 para 120 anos; (3) a inserção, além dos percentuais, dos números de casos de nós e a gente para cada um dos períodos analisados; (4) uma amostra completa, por personagens, dos usos de nós e a gente, detalhando-se as faixas etárias, sexo e classe social; (5) o cruzamento entre os resultados das variáveis sociais; (6) o aprofundamento das condições sócio-históricas das obras, dos autores e das comunidades, para se tenha um melhor detalhamento das reais condições sociais do processo de mudança; (7) a verificação da região geográfica dos autores e do contexto dos personagens das peças de teatro analisadas; (8) a possibilidade de ampliação e refinamento da variável classe social, com a ideia de verificação de uma "rede social histórica"; (9) a viabilidade de realização de uma comparação entre diálogos de peças de teatro e de outros gêneros textuais (especialmente de textos narrativos) do(s) mesmo(s) período(s) histórico(s) (cf. AYRES-BENNET, 2018).

Todas essas propostas são factíveis, uma vez que temos a possibilidade de revisitar os dados atuais e utilizá-los sob uma outra perspectiva metodológica e analítica, que contemple mais detalhadamente os princípios e os procedimentos voltados para a análise Sociolinguística Histórica.
Proposta metodológica de descrição e análise de fenômenos variáveis em textos históricos na perspectiva da sociolinguística histórica 
Paulo Ricardo

Silveira Borges

Tatiana Keller

\section{Considerações finais}

Buscou-se, com este texto, apresentar uma proposta metodológica para a análise de fenômenos variáveis em textos históricos, levando-se em conta os procedimentos dispostos na teoria da sociolinguística histórica. Outras questões metodológicas merecerão atenção especial em uma nova análise sociolinguística que deverá ser realizada a partir do corpus utilizado neste trabalho, composto de onze peças de teatro de autores gaúchos, correspondendo a um período histórico de 100 anos. Além disso, pretendemos acrescentar duas novas peças de teatro, correspondendo aos períodos de 2000 e 2010, estendendo-se o período histórico para 120 anos. Soma-se a isso, outros fatores como contexto de uso, linguagem mais formal/informal, contexto de produção do texto, tipo de norma utilizada, diferenças estilísticas entre os autores, entre outros aspectos que deverão merecer uma atenção mais detalhada.

Acreditamos que o gênero textual peça de teatro seja propício para uma análise sociolinguística variacionista, haja vista que os contextos histórico-sociais das comunidades de fala podem estar contemplados, em maior ou menor grau, nos diálogos dos personagens presentes nas peças. Neste aspecto, a proposta aqui apresentada de análise sociolinguística histórica, a partir da utilização de textos de teatro de diferentes períodos, mostrou o quanto é produtiva a análise na perspectiva da sociolinguística com fontes documentais históricas para a explicação dos processos de mudança linguística e a melhor compreensão dos fatores sociais que atuaram para que determinada mudança linguística ocorresse.

A análise apresentada, com os exemplos dos dados sociais das peças de teatro analisadas por Borges (2004), indica ser possível a utilização dos dados sociolinguísticos do passado para explicar o presente, levando-se em conta os preceitos da linguística histórica para a análise dos fenômenos de mudança linguística e suas correlações com os fatores sociais. Nesse aspecto, a proposta metodológica aqui apresentada, dentro dos seus limites de análise, abre novos caminhos para a análise dos dados variáveis, mostrando que a variação linguística está presente em diferentes momentos da história de uma língua, influenciada pelos contextos sócio-históricos das comunidades onde esta língua é utilizada. 
AITCHISON, Jean. Diachrony vs. Synchrony: the complementary evometodológica lution of two (ir)reconciliable dimensions. In: HERNÁNDEZ-CAMPOY, Juan. Manuel; CONDE-SILVESTRE, Juan Camilo (eds). The Handbook of Historical Sociolinguistics. London: Balckwell, p. 22-40, 2012.

AMARAL, Luís Isaías Centeno. A concordância verbal de segunda pessoa no singular em Pelotas e suas implicações linguísticas e sociais. Tese (Doutorado em Letras), Instituto de Letras, Universidade Federal do Rio Grande do Sul, Porto Alegre, 2003.

de descrição e análise de fenômenos variáveis em textos históricos na perspectiva da sociolinguística histórica

AYRES-BENNET, Wendy. Historical Sociolinguistics and tracking language: sources, text types and genres. In: AYRES-BENNET, Wendy; CARRUTHERS, Janice. (eds). Manual of Romance Sociolinguistics. Berlin: De Gruyter, p. 253-279, 2018.

BORBA, Lilian do Rocio. Alguns aspectos sobre o uso de "nós" e "a gente" em Curitiba. Fragmenta, Curitiba, UFPR/CPGL, n. 10, p. 65-76, 1993.

BORGES, Paulo Ricardo Silveira. A gramaticalização de 'a gente' no português brasileiro: análise histórico-social-linguística da fala das comunidades gaúchas de Jaguarão e Pelotas. Tese (Doutorado em Letras). Instituto de Letras. Universidade Federal do Rio Grande do Sul, Porto Alegre, 2004.

CONDE-SILVESTRE, Juan Camilo. Sociolingüística histórica. Madrid: Gredos, 2007.

ECKERT, Penelope. The whole woman: sex and gender differences in variation. In: COUPLAND, Nikolas; JOWORSKI, Adam. (Eds.). Sociolinguistics: a reader and coursebook. New York: Martin's Press, p. 212-228, 1997.

Age as a sociolinguistic variable. In: COULMAS, Florian. (org.). The handbook of sociolinguistics. Oxford: Blackwell, 2007.

GUY, Gregory. Language and social class. Linguistics: The Cambridge Survey, v. 4, 1987. 
HERNÁNDEZ-CAMPOY, Juan Manuel; CONDE-SILVESTRE, Juan Camilo (eds). The Handbook of Historical Sociolinguistics. London: Balckwell, p. 22-40, 2012.

LABOV, William. Sociolinguistic patterns. Philadelphia: University of Pennsylvania Press, 1972.

Paulo Ricardo Silveira Borges Principles of linguistic change: internal factors. Oxford: Blackwell, 1994.

Tatiana Keller Principles of linguistic change: social factors. Oxford: Blackwell, 2001.

LOPES, Célia Regina dos Santos. Nós e a gente no português falado culto do Brasil. Rio de Janeiro, Dissertação (Mestrado em Letras), Faculdade de Letras, UFRJ, 1993.

. A inserção de "a gente" no quadro pronominal do português: percurso histórico. Rio de Janeiro. Tese (Doutorado em Letras), Faculdade de Letras, UFRJ, 1999.

.et al. Reflexões metodológicas para a análise sociocultural de redatores em corpora históricos. Gragoatá, Niterói, n. 29, p. 239-253, 2010.

LUCCHESI, Dante. A periodização da história sociolinguística do Brasil. D.E.L.T.A., n. 33, v. 2, p. 347-382, 2017.

MAIA, Clarinda. Linguística Histórica e Filologia. In LOBO, Tânia [et al.]. Rosae: linguística histórica, história das línguas e outras histórias. Salvador: EDUFBA, p. 533-542, 2012.

MAMBRINI, Ester. Teatro e variação: a colocação pronominal em duas versões de 'A Viúva Pitorra' de João Simões Lopes Neto. Dissertação de Mestrado, Instituto de Letras, Universidade Federal do Rio Grande do Sul, Porto Alegre, 2004.

MARCOTULIO, Leonardo Lennertz et al. Filologia, história e língua: olhares sobre o português medieval. São Paulo: Parábola, 2018. 
MARQUILHAS, Rita. Non-anachronism in the historical sociolinguistic study of Portuguese. Journal of Historical Sociolinguistics, 1(2), p. 213- 242, 2015.

MATTOS E SILVA, Rosa Virgínia. o português arcaico: fonologia, morfologia e sintaxe. São Paulo: Editora Contexto, 2006 [1991].

. Ensaios para uma sócio-história do português brasileiro. São Paulo: Parábola, 2004.

MEDINA MORALES, Francisca. Problemas metodológicos de la sociolinguística histórica. Forma y Función, n. 18, p. 115-137, 2005.

MENON, Odete Pereira da Silva. A gente: um processo de gramaticalização. Estudos linguísticos, Anais de Seminários do GEL, Taubaté, 1996.

MONTEIRO, José Lemos. Pronomes pessoais: subsídios para uma gramática do português do Brasil. Fortaleza: Edições UFC, 1994.

MONTGOMERY, Martin. Variation and historical linguistics. In: BAYLEY, Robert; LUCAS, Ceil. (Eds.). Sociolinguistic variation: theories, methods and applications. Cambridge: Cambridge University Press, p. 110-132, 2007.

NEVALAINEN, Terttu; RAUMOLIN-BRUNBERG, Helena. Historical Sociolinguistics: origins, motivations, and paradigms. In: HERNÁNDEZ-CAMPOY, Juan. Manuel; CONDE-SILVESTRE, Juan Camilo Conde. (eds). The Handbook of Historical Sociolinguistics. London: Balckwell, p. 22-40, 2012.

OLIVEIRA, Marco Antônio. Nem tudo que reluz é ouro: língua escrita e mudança linguística. Scripta. Belo Horizonte, v. 8, n. 16, p. 165-175, 2005.

OMENA, Nelise Pires de. A referência variável da primeira pessoa do discurso no plural. In: NARO, Anthony Julius [et al.]. Relatório final de pesquisa: projeto subsídios do projeto censo à educação. Rio de Janeiro: UFRJ, v. 2, p. 286-319, 1986.
Proposta metodológica de descrição e análise de fenômenos variáveis em textos históricos na perspectiva da sociolinguística histórica 
As influências sociais na variação entre nós e a gente na função de sujeito. In: OLIVEIRA E SILVA, Giselle Machline; SCHERRE, Maria Marta Pereira. Padrões sociolingüísticos: análise de fenômenos variáveis do português falado na cidade do Rio de Janeiro. Rio de Janeiro: Tempo Brasileiro. Departamento de Lingüística e Filologia, UFRJ, p. 309-323, 1996.

PRETI, Dino. Sociolinguística: os níveis de fala, um estudo sociolinguístico

Paulo Ricardo do diálogo na literatura brasileira. São Paulo: Editora Nacional, 1974.

Silveira Borges

Tatiana Keller

ROMAINE, Suzanne. Socio-historical linguistics: its status and methodology. Cambridge: Cambridge University Press, 1982.

ROSA, Eliane da. Sociolinguística histórica. Revista de Letras, Curitiba, v.17, n. 21, p. 2015.

RUSSI, Cinzia. Introduction. In: RUSSI, Cinzia (ed.). Current Trends in Historical Sociolinguistics. Berlin: De Gruyter, 2016.

SCHNEIDER, Edgar Werner. Investigating Variation and Change in Written Documents. In: CHAMBERS, J. K.; TRUDGILL, Peter; SCHILLING-ESTES, Natalie. The Handbook of Language Variation and Change. Oxford: Blackwell, p. 67-96, 2002.

SEARA, Izabel Christine. A variação do sujeito 'nós' e 'a gente' na fala florianopolitana. Organon, v. 14, n. 28/29, 2000.

SILVA NETO, Serafim da. Língua, cultura e civilização. Rio de Janeiro: Acadêmica, 1960.

WEINREICH, Uriel; LABOV, William; HERZOG, Marvin. Empirical foundations for a theory of language change. In: LEHMANN, Winfred; MALKIEL, Yakov. (eds.). Directions for historical linguistics. Austin: University of Texas Press, 1968.

ZILLES, Ana Maria Stahl. Grammaticalization of a gente in Brazilian Portuguese. In: JOHNSON, Daniel Ezra; SANCHES, Tara. (eds.). University of Pennsylvania Working Papers in Linguistics (Papers from NWAV 30), v. 8, n. 3, p. 297-310, 2002. 
- O que a fala e a escrita nos dizem sobre a avaliação social do uso de a gente? Letras de Hoje. Porto Alegre, v. 42, n. 2, p. 27-44, 2007.

\section{REFERÊNCIAS BIBLIOGRÁFICAS DAS PEÇAS DE TEATRO}

ABREU, Caio Fernando. Pode ser que seja só o leiteiro lá fora. In. Teatro completo. Porto Alegre: Sulina, 1997.

BENDER, Ivo Cláudio. Bye, bye sweet home! In. Nove textos breves para teatro. Porto Alegre: Editora da UFRGS, 1985.

BORGES, Luís Pery. Seis anos de rádio: história anedótica de Pery \& Estellita - sketches e crônicas. Porto Alegre: Thurmann, 1942.

CONTE, Júlio. A coisa certa. Porto Alegre: WS Editor, 1998.

HECKER FILHO, Paulo. Quando elas querem. Porto Alegre: Teatro Universitário, 1958

FARIA-ROSA, Abadie. Nossa terra: comédia em três atos. Rio de Janeiro: Publicações Braz Lauria, 1917.

FORNARI, Ernani. Iaiá Boneca. Rio Grande do Sul: Editora Ministério da Educação, 1938.

LOPES NETO, João Simões. A viúva Pitorra [manuscrito], 1896.

MOREIRA, Álvaro. Adão, Eva e outros membros da família. [cópia]. 1927.

RUZICKI, Valdir. A ponte. Porto Alegre: Livraria do Globo, 1962.

TORRES, Joaquim Alves. A ciumenta velha. 1905. [In: Teatro social. Porto Alegre: IEL, 1989.].
Proposta

metodológica

de descrição

e análise de

fenômenos

variáveis

em textos

históricos na

perspectiva da

sociolinguística

histórica

75 
